\title{
Classification of sagittal imbalance based on spinal alignment and compensatory mechanisms
}

\author{
Claudio Lamartina $\cdot$ Pedro Berjano
}

Received: 6 July 2013/Revised: 31 January 2014/Accepted: 31 January 2014/Published online: 28 February 2014

(C) The Author(s) 2014. This article is published with open access at Springerlink.com

\begin{abstract}
Introduction Sagittal balance is an independent predictor of clinical outcomes in spinal care. Surgical treatment is challenging and jeopardized by frequent complications. Guidelines for surgical treatment are currently not based on a classification of the disease. A comprehensive classification of sagittal balance based on regional deformities and compensatory mechanisms combined in deformity patterns is proposed. Though the sagittal shape of the spine can change due to degeneration or trauma, correlations between sagittal shape parameters and pelvic incidence (PI) have been described. Pelvic incidence is not changed by degeneration, thus representing a permanent source of information on the original sagittal shape of the spine.

Methods One hundred and twenty-eight full-spine lateral standing radiographs of patients with different spinal conditions were evaluated and classified by one rater. One random subseries of 35 patients was evaluated by two raters for calculation of inter-rater agreement. Spinopelvic parameters were measured in all the radiographs. Internal validity of the classification system was evaluated comparing the values of regional sagittal parameters that distinguish one category from the others.

Results Eight different patterns were identified regarding the site of the deformity and the presence of compensatory mechanisms: cervical, thoracic, thoracolumbar junction, lumbar, lower lumbar, global and pelvic kyphosis and
\end{abstract}

\section{Lamartina}

II Division of Spinal Surgery, IRCCS Istituto Ortopedico

Galeazzi, Milan, Italy

P. Berjano $(\bowtie)$

IV Division of Spinal Surgery, IRCCS Istituto Ortopedico

Galeazzi, Via Riccardo Galeazzi, 4, 20161 Milan, Italy

e-mail: pberjano@gmail.com normal sagittal alignment. Inter-rater agreement was almost perfect $(\kappa=0.963)$. Statistically significant differences were found comparing the means of selected sagittal spinopelvic parameters that conceptually divide pairs or groups of categories: C2-C7 SVA for cervical kyphosis vs all other patients, TK-PI mismatch for thoracic kyphosis vs all other patients, T11-L2 kyphosis for thoracolumbar kyphosis vs all other patients, global alignment (LL+TK-PI) and SVA for lumbar kyphosis vs global kyphosis and pelvic tilt for pelvic kyphosis vs lumbar, lower lumbar and global kyphosis.

Conclusion A comprehensive classification of sagittal imbalance is presented. This classification permits a better interpretation of the deformity and muscle forces acting on the spine, and helps surgical planning. Preliminary validation has been provided.

Keywords Sagittal imbalance $\cdot$ Compensatory mechanisms · Classification $\cdot$ Clinical outcomes

\section{Introduction}

Sagittal balance reflects a shape of the spine that allows it to keep the standing position with little muscle effort [1]. The shape of the spine is the result of the sum of the shapes of bony elements (the vertebrae) and discs. Bone resists compression and keeps its shape under physiological compressive forces. Discs are also resistant to compression, and can keep a definite shape under physiological compression forces. It is necessary to apply a torque on the vertebral segment to create a deformation of the spine in flexion-extension (the directions of deformation relevant to sagittal balance). A degenerated disc loses to some extent its ability to keep the disc space shape and deforms under 
physiological compression forces [2], being flexion the most frequent direction of the deformation (causing sagittal anterior displacement of the spine). If the disc degeneration is coronally asymmetrical, physiological compression forces can cause in the disc a combined deformation in flexion (kyphosis) and lateral bending (scoliosis), usually coupled with axial torsion (rotation). Thus, an effect of aging on the spine is the trend toward loss of sagittal alignment. Other factors that can cause impairment of sagittal alignment are fractures (through kyphotic changes in bone shape), congenital or developmental deformities (as posterior hemivertebra, anterior bone bridges or combined disc and bone deformity, like in Scheuermann's disease).

Sagittal balance status has been demonstrated to be an independent predictor of clinical status and outcomes in subjects with adult scoliosis [3], in patients undergoing surgery for adult deformity [4], degenerative disc disease [5] and degenerative spondylolisthesis [6]. Surgical correction of sagittal imbalance has correlated with clinical improvement [7].

Much of the research effort in this field has focused on calculation of the amount of correction needed in degenerative or postsurgical sagittal imbalance $[1,8-10]$ and identification of ideal fusion levels in thoracic kyphosis (TK) [11]. Some problems remain unsolved, such as the ideal proximal level to fuse in degenerative or postsurgical imbalance, or identification of patients at risk of proximal junctional kyphosis [12]. Extension of the fusion area has also an influence on the incidence of complications [13].

Currently, no comprehensive classification of sagittal spinal deformities exists. Surgical treatment is guided by specific rules by anatomical region (i.e. for thoracic kyphosis, lumbar flat-back syndrome, etc.). A comprehensive classification of sagittal deformities that could help clinicians to improve the understanding of the condition, make possible comparison of outcomes and assist surgical planning would be desirable. The aim of this paper is to present a classification of sagittal spinal deformities based on the level of the deformity and the existing compensatory mechanisms.

\section{Methods}

Study design Retrospective cohort study.

\section{Subjects}

One hundred and twenty-eight full-spine lateral standing radiographs obtained from patients without previous spinal surgery referred to a spinal center, with a broad spectrum of spinal pathologies, were collected. The following spinopelvic parameters were measured from the radiographs: pelvic incidence (PI), pelvic tilt (PT), lumbar
Table 1 Basic principles of the classification

For a given patient, an ideal sagittal alignment can be predicted Sagittal appearance of the standing spine and pelvis is the result of the combination of regional deformity (or deformities) and its interaction with compensatory mechanisms. This combination determines the presentation of sagittal deformity patterns

Surgical treatment addresses correction of regional deformity and/ or eliminates the need for active muscle contraction to compensate regional deformity

The presence of compensatory mechanisms can help estimate the ability of the spine to maintain correct alignment of segments left mobile after correction of the deformity

The absence of compensatory mechanisms can determine the need to extend correction to segments not involved in the primary sagittal deformity

Eventually, some patterns of imbalance in the absence of expected compensatory mechanisms can be explained by the presence of abnormal schemes of neurological motor activation

lordosis (LL), L4-S1 lordosis ( $\left.\mathrm{L}_{\mathrm{L} 4-\mathrm{S} 1}\right)$, thoracolumbar lordosis $\left(\mathrm{L}_{\mathrm{T} 11-\mathrm{L} 2}\right)$, thoracic kyphosis, $\mathrm{C} 7-\mathrm{S} 1$ sagittal vertical axis (SVA) and C2-C7 sagittal vertical axis (C2-C7 SVA). Previously published formulae and data were used to estimate the ideal sagittal parameters based on pelvic incidence $[9,14,15]$. Two senior spinal surgeons evaluated all the films and after discussion defined eight deformity patterns (including normal sagittal alignment). One blinded rater classified all the films in one of the eight categories.

Each deformity pattern was described by PI, PT, LL, $\mathrm{L}_{\mathrm{L} 4-\mathrm{S} 1}, \mathrm{~L}_{\mathrm{T} 11-\mathrm{L} 2}$, TK, SVA and C2-C7-SVA, expressed as mean and standard deviation.

For evaluation of external validity of the classification, one subset of 35 radiographs was independently evaluated by a second rater for calculation of inter-rater agreement.

Internal validity of the classification system was evaluated comparing the values of regional sagittal parameters that distinguish one category from the others.

Statistical analysis Inter-rater agreement was evaluated with the Kappa statistic. Means were compared with the Student's $t$ test for independent variables. Statistical significance threshold was set at $p<0.05$.

\section{Methodological principles}

This classification method assumes that for a given patient, ideal sagittal alignment of the spine can be predicted. Previous papers have identified formulae that allow calculation of ideal lumbar lordosis and pelvic tilt from pelvic incidence $[9,14]$. Other provides data to calculate ideal thoracic kyphosis [15].

In this paper, sagittal imbalance is analyzed as a result of the interaction of regional deformities and compensatory mechanisms to present as deformity patterns. 
Table 2 Deformity patterns

\begin{tabular}{|c|c|c|}
\hline Deformity patterns & Regional deformity & Compensatory mechanisms \\
\hline $\begin{array}{l}\text { Normal sagittal } \\
\text { alignment }\end{array}$ & None & None \\
\hline Cervical kyphosis & Cervical kyphosis & Lumbar hyperlordosis or thoracic lordosis \\
\hline Thoracic kyphosis & Thoracic kyphosis & $\begin{array}{l}\text { Cervical hyperlordosis } \\
\text { Lumbar hyperlordosis }\end{array}$ \\
\hline $\begin{array}{l}\text { Thoracolumbar } \\
\text { kyphosis }\end{array}$ & Thoracolumbar kyphosis & $\begin{array}{l}\text { Lower lumbar hyperlordosis } \\
\text { Pelvic retroversion }\end{array}$ \\
\hline Lumbar kyphosis & Lumbar kyphosis & $\begin{array}{l}\text { Thoracic lordosis } \\
\text { Pelvic retroversion (flexed knees) }\end{array}$ \\
\hline $\begin{array}{l}\text { Lower lumbar } \\
\text { kyphosis }\end{array}$ & Lower lumbar kyphosis & $\begin{array}{l}\text { Upper lumbar hyperlordosis and/or pelvic } \\
\text { retroversion }\end{array}$ \\
\hline Global kyphosis & $\begin{array}{l}\text { Lumbar kyphosis normal or } \\
\text { increased thoracic kyphosis }\end{array}$ & $\begin{array}{l}\text { Increased pelvic tilt } \\
\text { Flexed knees }\end{array}$ \\
\hline Pelvic kyphosis & $\begin{array}{l}\text { Increased SVA with normal } \\
\text { spine or minor regional } \\
\text { kyphosis }\end{array}$ & $\begin{array}{l}\text { No compensatory mechanisms. Normal pelvic } \\
\text { tilt }\end{array}$ \\
\hline
\end{tabular}

A regional deformity is defined as sagittal kyphotic misalignment that affects a limited number of segments of the spine (i.e. the lumbar spine, the thoracic spine, the thoracolumbar junction or the lower lumbar spine).

Compensatory mechanisms are changes in the sagittal alignment of spinal or non-spinal segments, different from those involved in regional deformity, in an attempt to restore the alignment of the gravity line or the horizontal gaze. Compensatory mechanisms need active muscle contraction by the subject.

Deformity patterns are the result of combining regional deformities and compensatory mechanisms and constitute the categories of this classification.

The basic principles of this classification system are summarized in Table 1.

\section{Regional deformities}

From rostral to caudal, the regional sagittal deformities of interest are

- Cervical kyphosis (CK): Kyphosis in the spine between the occiput (C0) and the 1st thoracic vertebra (T1).

- Thoracic kyphosis (TK): Kyphosis between the 1st thoracic vertebra (T1) and the 12th thoracic vertebra (T12).

- Thoracolumbar junction kyphosis (TLJK): Kyphosis between the 11th thoracic vertebra (T11) and the 2nd lumbar vertebra (L2).

- Lumbar kyphosis (LK): Kyphosis between the 1st lumbar vertebra (L1) and the sacrum (S1).

- Lower lumbar kyphosis (LLK): Kyphosis between the 4th lumbar vertebra (L4) and the sacrum (S1).

- Pelvic kyphosis (PK): Flexion at the hip joints.
In this paper, the term kyphosis refers to any alignment of a region with more kyphosis or less lordosis than predicted.

Compensatory mechanisms

From rostral to caudal, the sagittal compensatory mechanisms are

- Cervical hyperlordosis: Increased lordosis between the occiput (C0) and the 1st thoracic vertebra (T1).

- Thoracic lordosis: Decreased kyphosis between the 1st thoracic vertebra (T1) and the 12th thoracic vertebra (T12).

- Lumbar hyperlordosis: Hyperlordosis between the 1st lumbar vertebra (L1) and the sacrum (S1).

- Upper lumbar hyperlordosis (L1-L3): Hyperlordosis between the 1st lumbar vertebra (L1) and the 4th lumbar vertebra (L4).

- Lower lumbar hyperlordosis (L4-S1): Hyperlordosis between the 4th lumbar vertebra (L4) and the sacrum (S1).

- Pelvic retroversion: Posterior rotation of the pelvis through extension of the hips; can be identified by increased pelvic tilt.

- Knee flexion: Flexion at the knees to translate posteriorly the center of mass respect to the feet and increase pelvic retroversion beyond the limit of hip extension. Knee flexion can be identified by femoral shaft inclination over $5^{\circ}$ in the sagittal plane.

In this paper, the term hyperlordosis refers to any regional alignment with more lordosis than predicted. 
Fig. 1 Cervical kyphosis.

a Clinical picture, b standing whole spine radiograph showing compensatory lumbar hyperlordosis, c detail of the cervical spine, and $\mathbf{d}$ detail of the pelvis standing: increased pelvic tilt is present, suggesting that the deformity involves the whole spine and pelvis

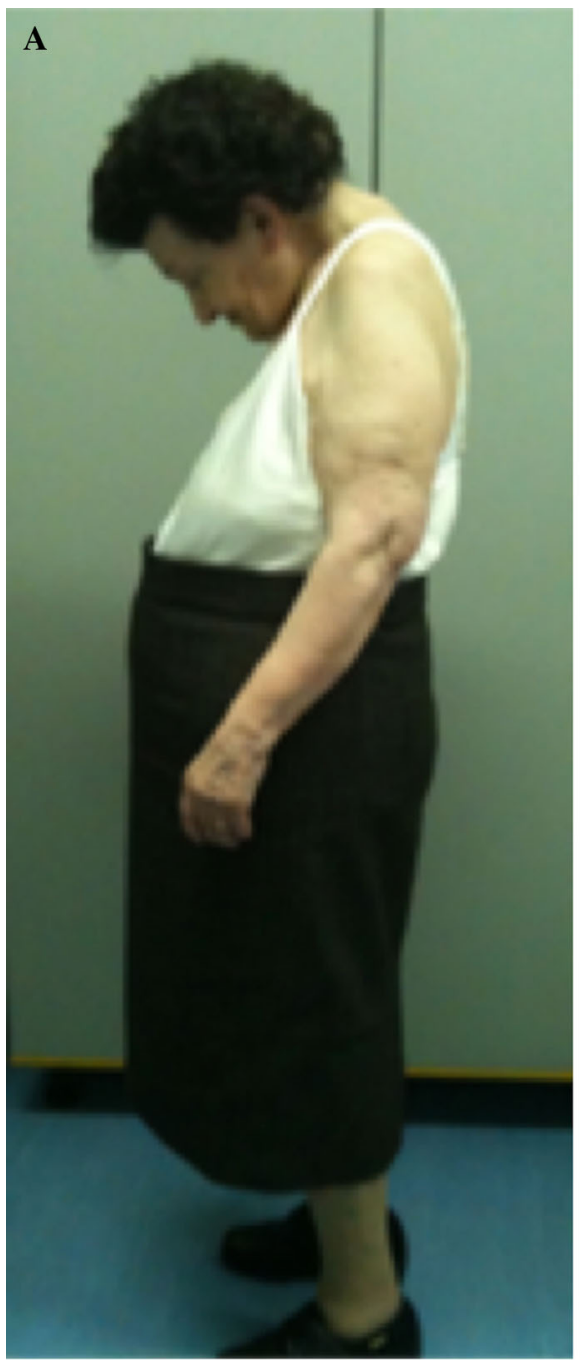

\section{B}
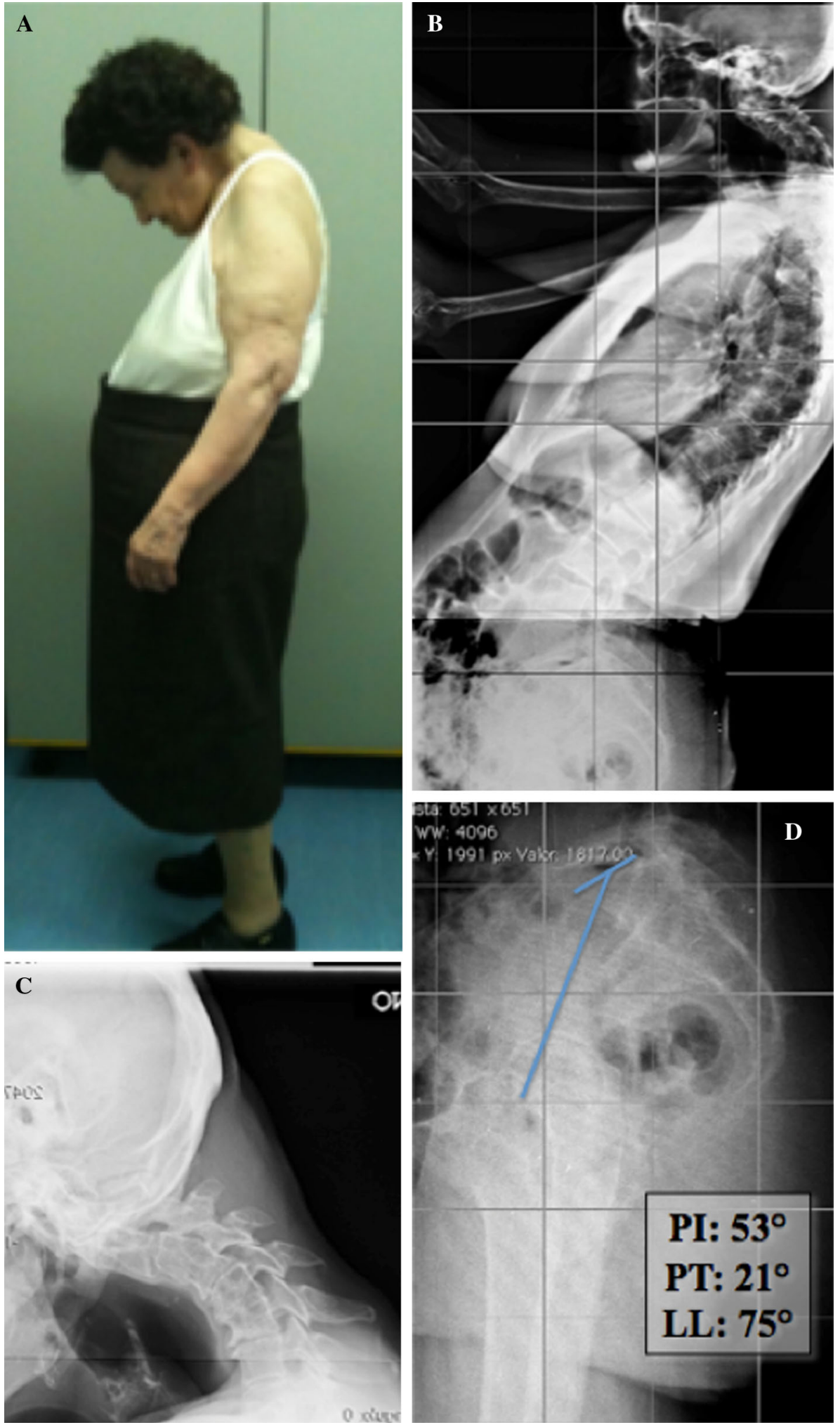

WW: 4096

D

F
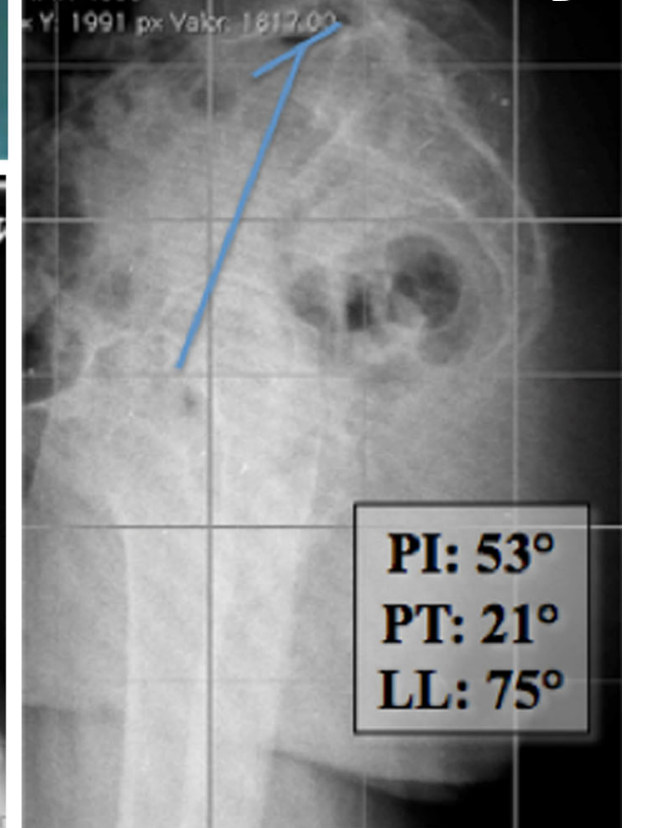

\section{Results}

Deformity patterns are described in Table 2 and illustrated in Figs. 1, 2, 3, 4, 5, 6, and 7. The classification is based on the position of the kyphotic region and the compensatory mechanisms present in the subject.

Table 3 presents the distribution of the cohort along the eight categories of spinal sagittal alignment patterns and 
Fig. 2 Thoracic kyphosis in Scheuermann's disease. a Clinical picture, b standing whole spine film showing lumbar hyperlordosis as a compensatory mechanism, and c after surgical correction of thoracic kyphosis, lumbar hyperlordosis is spontaneously corrected
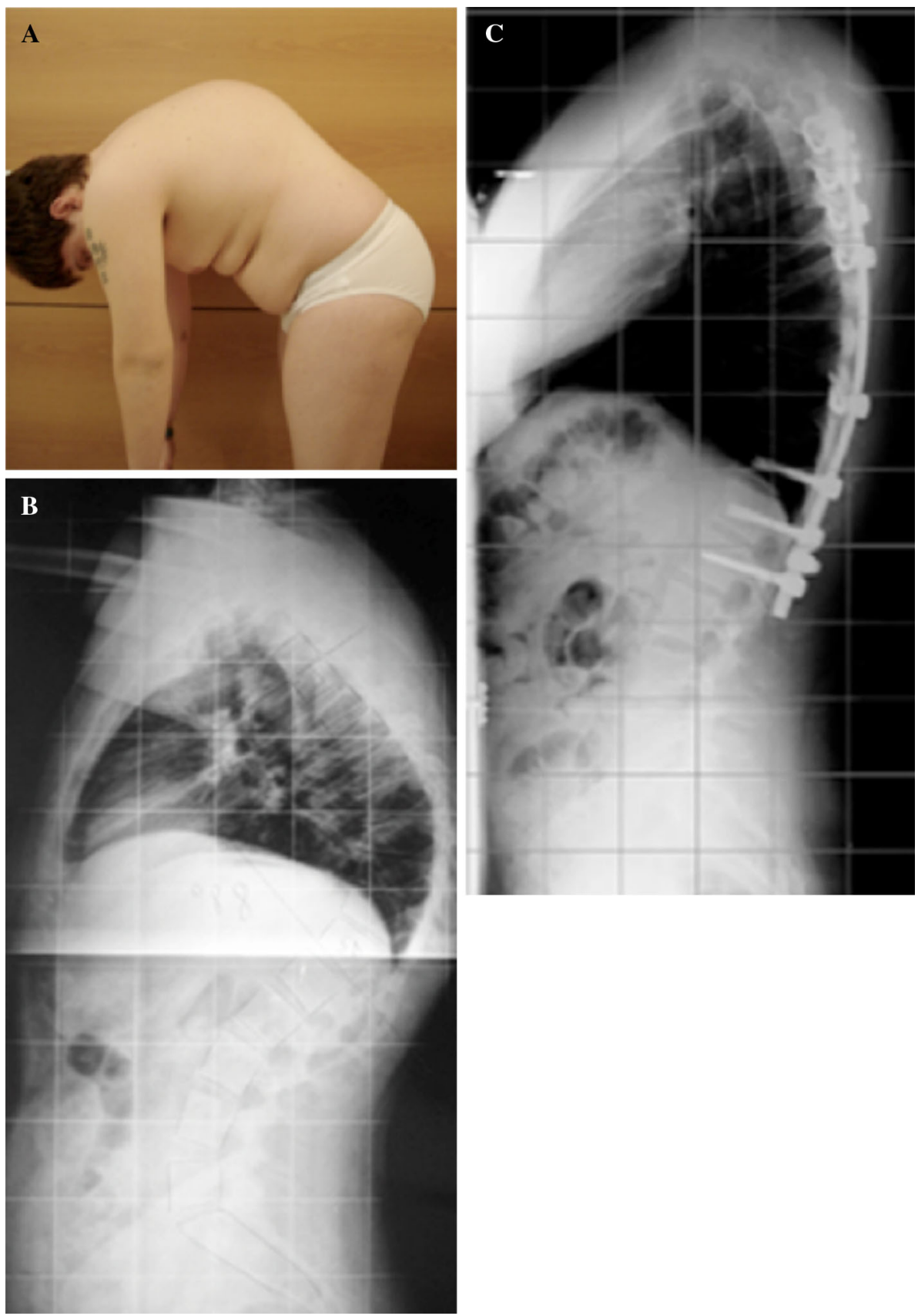

Other authors have identified a higher risk of proximal junctional kyphosis after fusion of the lumbar spine stopping at the lower thoracic spine [12]. Atrophy of the extensor muscles in the thoracolumbar spine and thoracolumbar junction kyphosis has been described by these authors as risk factors for global kyphosis opposed to lumbar kyphosis.

Isolated thoracolumbar kyphosis frequently results from fractures in the thoracolumbar junction. This type of lesion has received little attention as a cause of sagittal imbalance. In our series, patients with thoracolumbar junction kyphosis have constantly presented compensation by lower lumbar 
Fig. 3 Type B fracture of L2 causing thoracolumbar junction kyphosis. a Detail of the segmental deformity, b whole spine standing film, showing increased lower lumbar lordosis and increased pelvic tilt as compensatory mechanisms, and c after correction of the regional deformity, lower lumbar lordosis and pelvic tilt are normalized, C7 plumbline translates posteriorly, demonstrating the global effect of the deformity
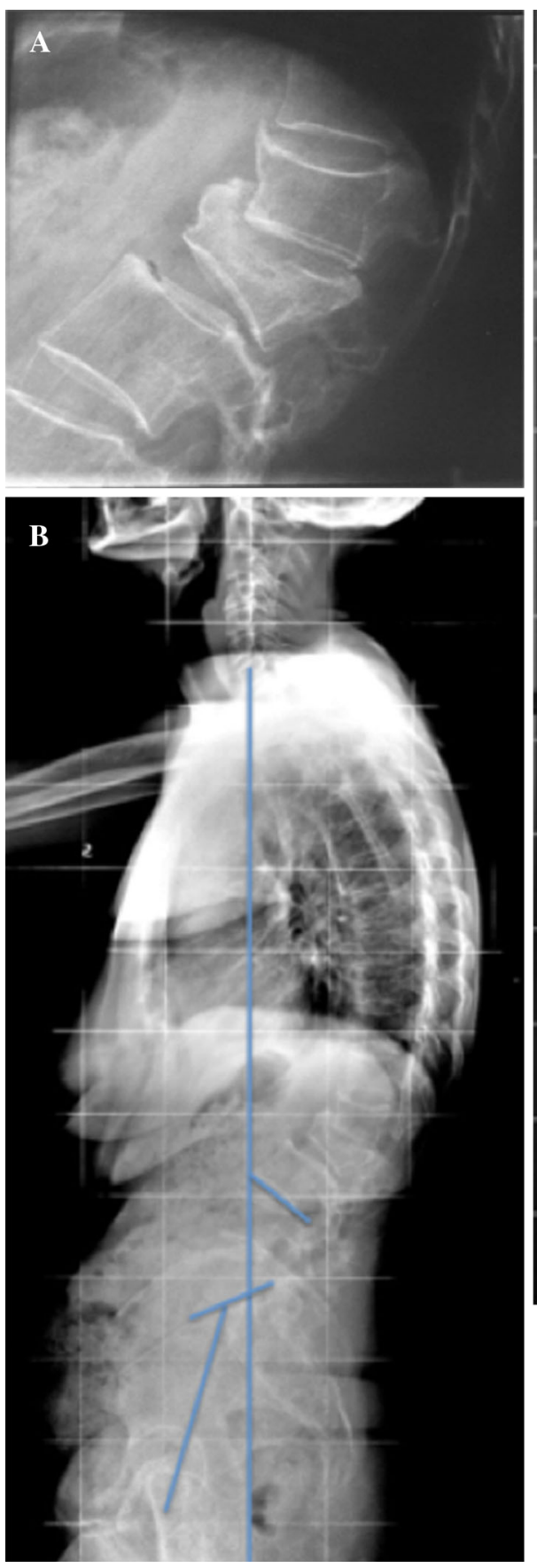

hyperlordosis and pelvic retroversion, which demonstrates that these patients are in a hidden imbalance status.

Lower lumbar kyphosis is defined as lordosis between the superior endplates of L4 and $\mathrm{S} 1<2 / 3$ of predicted lumbar lordosis, as expected in asymptomatic individual. This is a frequent situation in degenerative disc disease. Including this category in the sagittal imbalance classification helps clinicians to better interpret patients with lower lumbar degenerative disease and better plan surgical treatment, with attention to restore or preserve lower lumbar lordosis.
Pelvic kyphosis has received little attention in the literature, and the authors believe that constitutes a distinct category in sagittal imbalance. These patients present with an increased SVA (C7 plumbline far anterior from S1 posterior corner), but they do not exhibit signs of pelvic compensation (pelvic tilt is not increases). As a result, an apparent harmonic spine or a spine with non-severe lumbar kyphosis is projected anteriorly without a pelvic retroversion to compensate for this misalignment. We have been able to identify this pattern in patients with neurological 


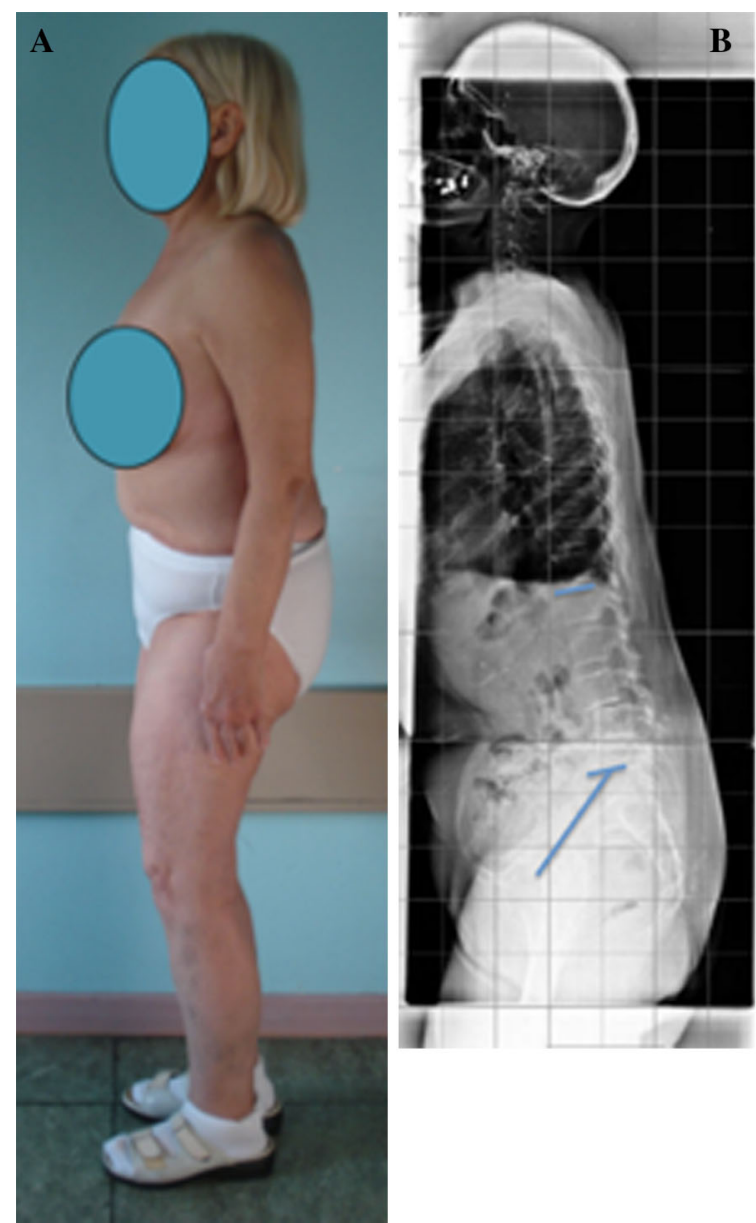

Fig. 4 Lumbar kyphosis. a Clinical picture showing knee flexion as a compensatory mechanism, b whole spine standing film shows all the compensatory mechanisms: thoracic lordosis, pelvic retroversion (showing as increased pelvic tilt) and knee flexion (presenting as femoral inclination). Lumbar kyphosis differs from global kyphosis in that in lumbar kyphosis a compensation by extension of the thoracic

disease, such as dystonia or Parkinson disease with poor response to pharmacological treatment. It is still unclear if every patient with pelvic kyphosis is a subject with neurological disease that causes an increase in flexor muscle activity. Nor it is clear if isolated hip disease with flexion contracture can be a second cause of pelvic kyphosis.

The external validity of the classification has been evaluated. The Cohen's Kappa $(\kappa)$ value for inter-rater agreement was 0.963 (weighted $\kappa=0.964$ ). The confidence interval was from 0.892 to 1.000 . Following the Landis and Koch's criteria, the whole $95 \%$ confidence interval represented an almost perfect agreement.

The internal validity of the classification was tested comparing the values of regional sagittal parameters that distinguish one category from the others (Table 4). Significant statistical differences between categories in key sagittal spinopelvic parameters that define distinct
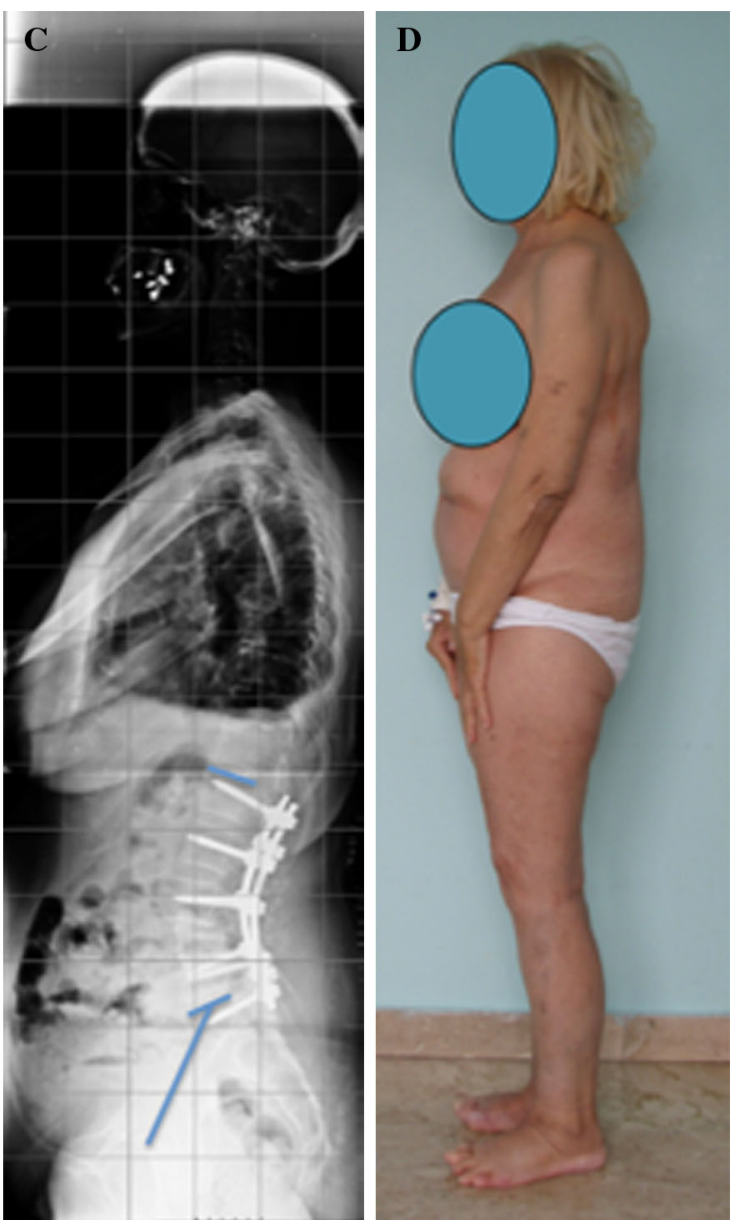

spine is present. This demonstrates the activity of the thoracic extensor muscles and is key to identify patients that can be treated excluding of the fusion area the mid- and high-thoracic spine, and c, d after selective fusion in the lumbar spine, the patient achieves excellent balance with reversal of compensatory mechanisms

categories from the others have been found for all the comparisons except for the L4-S1 lordosis between lumbar and lower lumbar kyphosis $(p=0.057)$.

\section{Discussion}

The most widely accepted classification of adult spinal deformity (the Schwab-SRS' classification of adult scoliosis [16]) includes three "sagittal modifiers". The reason for this parameter is that strong evidence has been presented in the literature regarding the key influence of sagittal alignment on clinical outcomes [17-21].

Normal sagittal alignment of the spine allows the individual to keep the horizontal gaze. Another important consequence of normal sagittal alignment is keeping the gravity line (a vertical line through the center of mass of 
Fig. 5 Lower lumbar kyphosis. a In this standing film degenerative disc disease at L5S1 causes loss of the physiological shape of the lumbar spine $(40 \%$ of total lordosis at L5-S1 and $65 \%$ of total lordosis at L4-S1), and b restoring lordosis at $\mathrm{L} 5-\mathrm{S} 1$ causes reduction of the compensatory hyperlordosis at L1-L5
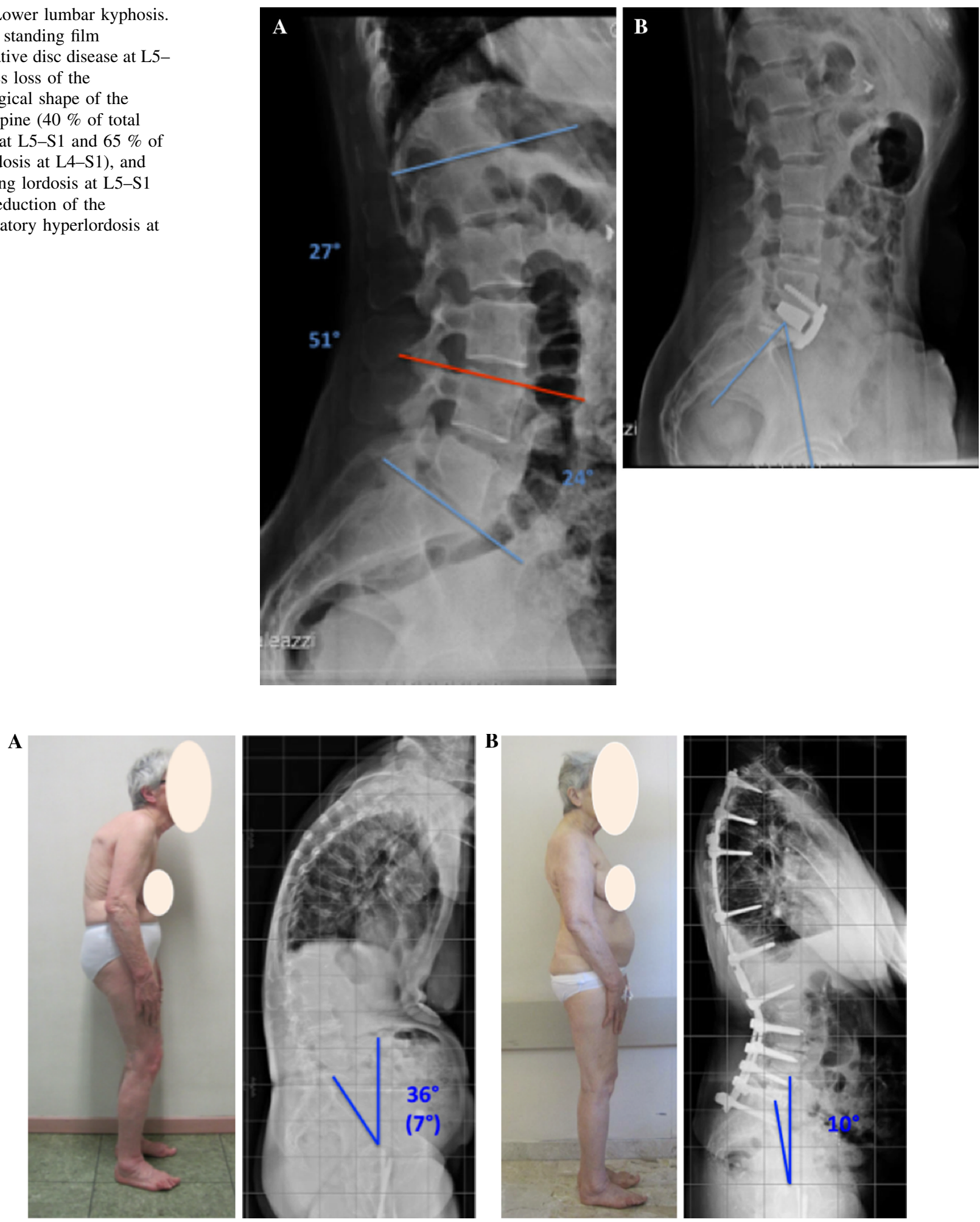

Fig. 6 Global kyphosis. a Lumbar kyphosis is not compensated by thoracic lordosis. This is the key aspect to differentiate global kyphosis from lumbar kyphosis. The thoracolumbar junction is kyphotic. Pelvic tilt is increased and knee flexion is present, showing the effect of compensatory mechanisms, $\mathbf{b}$ the failure of the thoracic spine to compensate indicates the need to include the thoracic spine in the fusion and instrumentation area. After restoring lumbar lordosis and thoracic kyphosis to expected values, pelvic tilt normalizes and knee flexion disappears 


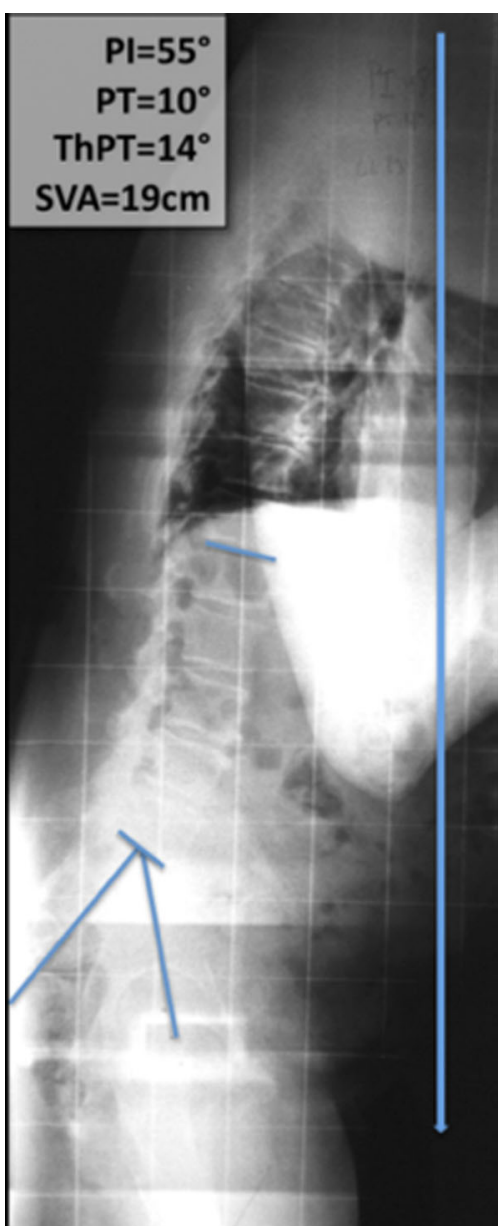

Fig. 7 Pelvic kyphosis. Insufficient lumbar lordosis $\left(23^{\circ}\right)$ respect to pelvic incidence $\left(55^{\circ}\right)$ alters sagittal balance. Increased pelvic tilt that would be expected is not present as a compensatory mechanism (expected pelvic tilt is $14^{\circ}$; measured pelvic tilt is $10^{\circ}$ ), resulting in abnormal translation of $\mathrm{C} 7$ plumbline $(19 \mathrm{~cm})$ without active compensation. This is a Parkinson's disease patient with resistance to L-dopa and camptocormia

the body) centered in the pelvis and the support area or the feet. This makes it possible to maintain the standing position without external support and with minimal muscular effort.

When segments of the spine deform due to the mechanisms mentioned above, the individual adapts the position of spinal segments to restore the global alignment. Frequently, this mechanism uses muscle force to improve alignment, with a resulting spinal shape that restores the gravity line position and horizontal gaze [22-24]. In this stage, the individual is able to meet these alignment goals, but at the price of increased muscle activity. By definition, this produces an imbalanced spine (the subject is not able to keep upright position with low muscle activity). This situation has been defined as compensated imbalance [1] or compensating imbalance [25]. We believe that the

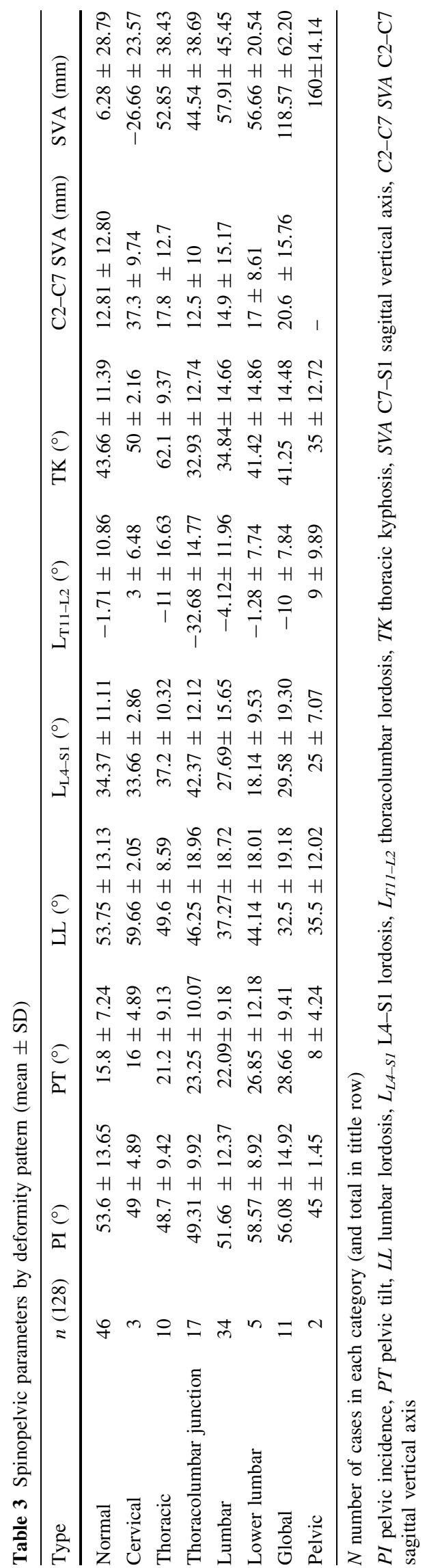


Table 4 Comparison between categories of parameters determining allocation to deformity pattern categories (Student's $t$ for independent means)

\begin{tabular}{|c|c|c|c|}
\hline \multirow[t]{2}{*}{ Parameter compared } & \multicolumn{2}{|l|}{ Categories compared } & \multirow[t]{2}{*}{$p$ value } \\
\hline & Between category & And category/ies & \\
\hline \multirow[t]{2}{*}{ C2-C7 SVA } & Cervical kyphosis & All the rest & 0.0049 \\
\hline & $37.3 \pm 9.74 \mathrm{~mm}(n=3)$ & $14.75 \pm 13.5 \mathrm{~mm}(n=120)$ & \\
\hline \multirow[t]{2}{*}{ TK-PI mismatch } & Thoracic kyphosis & All the rest & $<0.0001$ \\
\hline & $13.40^{\circ} \pm 7.69(n=10)$ & $-13.38^{\circ} \pm 17.10(n=118)$ & \\
\hline \multirow[t]{2}{*}{$\mathrm{L}_{\mathrm{T} 11-\mathrm{L} 2}$} & Thoracolumbar junction kyphosis & All the rest & $<0.0001$ \\
\hline & $42.37^{\circ} \pm 12.12(n=16)$ & $-3.79^{\circ} \pm 11.90(n=112)$ & \\
\hline \multirow{2}{*}{$\mathrm{L}_{\mathrm{L} 4-\mathrm{S} 1}$} & Thoracolumbar junction kyphosis & Lumbar, lower lumbar, and global kyphosis & 0.0009 \\
\hline & $\left.42.37^{\circ} \pm 12.12 n=16\right)$ & $26.84^{\circ} \pm 16.49(n=52)$ & \\
\hline \multirow[t]{2}{*}{ LL-PI mismatch } & Lumbar kyphosis & Global kyphosis & 0.0722 \\
\hline & $-14.5^{\circ} \pm 17.96(n=32)$ & $-23.58^{\circ} \pm 12.8(n=12)$ & \\
\hline \multirow[t]{2}{*}{$(\mathrm{LL}+\mathrm{TK})$-PI mismatch } & Lumbar kyphosis & Global kyphosis & 0.0394 \\
\hline & $49.24^{\circ} \pm 20.43(n=32)$ & $64.83^{\circ} \pm 20.98(n=12)$ & \\
\hline \multirow[t]{2}{*}{ SVA } & Lumbar kyphosis & Global kyphosis & 0.007 \\
\hline & $57.91^{\circ} \pm 45.45$ & $118.57^{\circ} \pm 62.2$ & \\
\hline \multirow[t]{2}{*}{$\mathrm{L}_{\mathrm{L} 4-\mathrm{S} 1}$} & Lumbar kyphosis & Lower lumbar kyphosis & 0.0578 \\
\hline & $27.53^{\circ} \pm 16.18(n=32)$ & $18.14^{\circ} \pm 9.53(n=7)$ & \\
\hline \multirow[t]{2}{*}{ PT } & Pelvic kyphosis & Lumbar, lower lumbar, global kyphosis & 0.0218 \\
\hline & $8^{\circ} \pm 3(n=2)$ & $20.67^{\circ} \pm 9.81(n=52)$ & \\
\hline
\end{tabular}

Table 5 Stages of sagittal alignment

\begin{tabular}{|c|c|c|}
\hline & Definition & Criteria \\
\hline Sagittally balanced & $\begin{array}{l}\text { The spine is able to align the gravity } \\
\text { line and keep horizontal gaze with } \\
\text { little muscle effort }\end{array}$ & $\begin{array}{l}\text { C7 plumbline is near posterior corner of S1 endplate (currently, } \\
\text { accepted maximum translation is } 25-50 \mathrm{~mm} \text { ) AND no } \\
\text { compensatory mechanisms are present }\end{array}$ \\
\hline Hidden sagittal imbalance & $\begin{array}{l}\text { The spine is able to align the gravity } \\
\text { line and keep horizontal gaze with } \\
\text { increased muscle effort }\end{array}$ & $\begin{array}{l}\mathrm{C} 7 \text { plumbline is near posterior corner of } \mathrm{S} 1 \text { endplate (currently, } \\
\text { accepted maximum translation is } 25-50 \mathrm{~mm} \text { ) BUT } \\
\text { compensatory mechanisms are present }\end{array}$ \\
\hline $\begin{array}{l}\text { Uncompensated sagittal } \\
\text { imbalance }\end{array}$ & $\begin{array}{l}\text { The spine is unable to align the gravity } \\
\text { line or keep the horizontal gaze }\end{array}$ & $\begin{array}{l}\text { C7 plumbline is beyond the accepted distance from posterior } \\
\text { corner of } \mathrm{S} 1 \text { endplate. Compensatory mechanisms are } \\
\text { lacking or insufficient }\end{array}$ \\
\hline
\end{tabular}

term hidden imbalance (Table 5) reflects better the biomechanical situation of this category of subjects.

Increasing deformity or inadequate muscle strength or endurance in the individual can make compensatory mechanisms to fail in achieving horizontal gaze and gravity line alignment. This situation is defined as uncompensated imbalance.

The classification here presented integrates the most common severe degenerative sagittal imbalance categories (lumbar kyphosis and global kyphosis), establishing a difference between them, based on the ability of the thoracic spine to compensate for imbalance (lumbar kyphosis) or not (global kyphosis). Two practical consequences arise from this distinction: first, lumbar kyphosis can potentially be treated by selective fusion of the lumbar deformity
(Table 6), while global kyphosis usually needs fusion of the thoracic spine and lumbar spine; second, after correction of lumbar deformity in lumbar kyphosis, an increase of thoracic kyphosis can be expected (as a consequence of postsurgical reduction of the amount of deformity needing compensation); if surgical planning is based on geometrical methods as the spinofemoral angle (SFA) method by Lamartina, Berjano et al. [1] or the full balance integrated method by LeHuec [10], the correction angle must be calculated anticipating the expected increase of thoracic kyphosis. The SFA method contains a rule to assist in this decision.

Other well-known sagittal deformities that previously have not been integrated in the interpretation of sagittal imbalance have been included in the classification. 
Table 6 Deformity patterns and suggested methods of correction

\begin{tabular}{|c|c|c|}
\hline Deformity patterns & Correction & Fusion levels \\
\hline Cervical kyphosis & $\begin{array}{l}\text { Cervical osteotomy in rigid deformity. Multilevel anterior } \\
\text { release and posterior fixation and fusion can be an } \\
\text { alternative in more flexible cases. }\end{array}$ & \\
\hline Thoracic kyphosis & Correction of kyphosis to predicted value & From T2 to sagittal stable vertebra [11] \\
\hline $\begin{array}{l}\text { Thoracolumbar } \\
\text { kyphosis }\end{array}$ & Correction of the kyphosis to neutral T11-L2 & $\begin{array}{l}\text { If the deformity is segmental, the minimum needed for } \\
\text { stability. If regional, all the thoracolumbar junction. } \\
\text { In some cases with kyphosis of more discs in the } \\
\text { thoracolumbar junction associated to thoracic } \\
\text { hyperkyphosis, after correction the levels to be fused } \\
\text { are as in the thoracic kyphosis pattern. }\end{array}$ \\
\hline Lumbar kyphosis & $\begin{array}{l}\text { Correction of lumbar kyphosis to its } \\
\text { predicted lordosis value }\end{array}$ & $\begin{array}{l}\text { If segmental, short fusion, only involving the diseased } \\
\text { levels. If regional, extend cranially to L } 2 \text { or T10 }\end{array}$ \\
\hline Lower lumbar kyphosis & $\begin{array}{l}\text { Correction of lower lumbar kyphosis to } \\
\text { the predicted lordosis value }\end{array}$ & $\begin{array}{l}\text { L4-S1 with restoration of L4-S1 lordosis. Otherwise, } \\
\text { longer, as needed to restore lumbar lordosis }\end{array}$ \\
\hline Global kyphosis & $\begin{array}{l}\text { Correction of thoracic kyphosis and lumbar lordosis to } \\
\text { predicted values }\end{array}$ & T2-Ilium \\
\hline Pelvic kyphosis & $\begin{array}{l}\text { Rule out hip disease (i.e. hip arthritis with flexion } \\
\text { contracture) or neurological disease (Parkinson's disease, } \\
\text { dystonia) }\end{array}$ & \\
\hline
\end{tabular}

Cervical kyphosis has received little attention in the literature. This can cause significant impairment due to loss of horizontal gaze, swallowing and mastication problems [26]. Surgical treatment by posterior cervical osteotomy has been described [27].

Thoracic kyphosis has usually been interpreted as a distinct condition. It has been included in the classification as the presence of compensatory mechanisms (increased lumbar lordosis) confirms that this condition usually causes a situation of imbalance with involvement of the whole spine.

The same applies to thoracolumbar kyphosis, usually interpreted as a local deformity without general consequences. Careful analysis of sagittal alignment shows in these cases the presence of lower lumbar hyperlordosis and increased pelvic tilt, which can be reversed by correction of the deformity (Fig. 3a-c).

Lower lumbar kyphosis is probably one of the most common sagittal imbalance conditions. Recent research [6] has shown that single level lumbar degenerative disc disease can cause increase in pelvic tilt to compensate misalignment. Interestingly, in that study patients with postoperative improvement of pelvic tilt had a higher probability of favorable outcomes, demonstrating that considering and preventing the global consequences of the apparently innocent lumbar degenerative disease can increase the chance of better outcomes.

Pelvic kyphosis is, to our knowledge, a newly described category of sagittal imbalance. Data in the literature on this condition are lacking. Future research will confirm or eliminate this category. The authors hypothesize that this pattern can be mainly due to neurological conditions causing predominant flexor muscle activity, which impedes compensatory mechanisms to present. A second cause of pelvic kyphosis could be fixed flexion of the hips due to osteoarthritis or inflammatory disease.

When analyzing differences in spinopelvic parameters between categories, significant differences are found regarding the variables involved in the differentiation of one versus another subgroup of patients. Thus, the pattern thoracic kyphosis shows a very significant difference in thoracic kyphosis-pelvic incidence mismatch (a modality of normalization of thoracic kyphosis considering the absolute value of pelvic incidence in the subject) compared to the rest of patients; the pattern thoracolumbar junction kyphosis shows a highly significant difference with the rest of patients regarding T11-L2 kyphosis; the pattern lumbar kyphosis differs significantly from Global Kyphosis in the amount of SVA and in global alignment (LL + TK - PI) mismatch (a value that normalizes, for a given pelvic incidence, the sum between the amount of loss in lumbar lordosis and the increase in thoracic kyphosis); the pattern lower lumbar kyphosis shows a greater loss of lower lumbar lordosis $\left(\mathrm{L}_{\mathrm{L} 4-\mathrm{S} 1}\right)$ if compared to the pattern lumbar kyphosis - in this case, the small amount of cases probably underpowers the comparison resulting in a borderline nonsignificant $p$ value $(p=0.578)$. The value of C2-C7 SVA is significantly increased in the cervical kyphosis pattern compared to all the rest of cases. Pelvic tilt is significantly lower in the pelvic kyphosis pattern compared to the combination of lumbar, lower lumbar and global kyphosis patterns. 
Through the classification there is a consistent difference, statistically significant in most cases, between categories regarding the parameters that are taken into account to differentiate one deformity pattern from the others. This reflects the soundness of the principles of classification and serves as a preliminary validation of its content.

In this paper, a method to estimate the predicted values for regional alignment has been applied, based on current literature. We believe that future research will refine the methods of estimation of regional and global alignment of the spine, and thus, it is likely that new modalities substitute the ones proposed in this article. Until research provides surgeons a more perfect method to calculate what the normal alignment of a symptomatic subject should be, the approximation proposed in this paper can be used to treat current patients, as it is the clinical practice of the authors.

Similarly, the methods of treatment proposed in this paper can be modified in future as the result of new research.

It is the belief of the authors that the method of analysis here proposed will be valid in that future too, hopefully with improved effectiveness from better estimation and prediction of surgical outcomes based on new research.

In conclusion, this study presents and discusses a new classification system of sagittal deformity patterns of the spine based on the segment involved in the deformity and on the compensatory mechanisms acting on the spine. External and internal validations have been preliminarily provided by almost perfect inter-rater agreement and statistically significant differences between categories in the values of key sagittal parameters. The classification can be helpful in defining the surgical plan for correction of the deformity.

Acknowledgments The authors thank Matteo Pejrona MD and Riccardo Cecchinato MD for their help reviewing and assessing radiographs, statistical analysis and manuscript organization.

\section{Conflict of interest None.}

Open Access This article is distributed under the terms of the Creative Commons Attribution License which permits any use, distribution, and reproduction in any medium, provided the original author(s) and the source are credited.

\section{References}

1. Lamartina C, Berjano P, Petruzzi M, Sinigaglia A, Casero G, Cecchinato R, Damilano M, Bassani R (2012) Criteria to restore the sagittal balance in deformity and degenerative spondylolisthesis. Eur Spine J 21(Suppl 1):S27-S31

2. White AA, Panjabi MM (1990) Clinical biomechanics of the spine, 2nd edn. J.B. Lippincott Company, Philadelphia

3. Mac-Thiong JM, Transfeldt EE, Mehbod AA, Perra JH, Denis F, Garvey TA, Lonstein JE, Wu C, Dorman CW, Winter RB (2009)
Can C7 plumbline and gravity line predict health related quality of life in adult scoliosis? Spine 34:E519-E527

4. Glassman SD, Berven S, Bridwell K, Horton W, Dimar JR (2005) Correlation of radiographic parameters and clinical symptoms in adult scoliosis. Spine 30:682-688

5. Videbaek TS, Bünger CE, Henriksen M, Neils E, Christensen FB (2011) Sagittal spinal balance after lumbar spinal fusion: the impact of anterior column support results from a randomized clinical trial with an eight- to thirteen-year radiographic followup. Spine 36:183-191

6. Kim MK, Lee SH, Kim ES, Eoh W, Chung SS, Lee CS (2011) The impact of sagittal balance on clinical results after posterior interbody fusion for patients with degenerative spondylolisthesis: a pilot study. BMC Musculoskelet Disord 5(12):69. doi:10.1186/ 1471-2474-12-69

7. Smith JS, Shaffrey CI, Glassman SD et al (2011) Risk-benefit assessment of surgery for adult scoliosis: an analysis based on patient age. Spine 36:817-824

8. Yang BP, Ondra SL (2006) A method for calculating the exact angle required during pedicle subtraction osteotomy for fixed sagittal deformity: comparison with the trigonometric method. Neurosurgery 59:ONS458-63

9. Aurouer N, Obeid I, Gille O, Pointillart V, Vital JM (2009) Computerized preoperative planning for correction of sagittal deformity of the spine. Surg Radiol Anat 31:781-792

10. Le Huec JC, Leijssen P, Duarte M, Aunoble S (2011) Thoracolumbar imbalance analysis for osteotomy ***planification using a new method: FBI technique. Eur Spine J 20:669-680

11. Cho KJ, Lenke LG, Bridwell KH et al (2009) Selection of the optimal distal fusion level in posterior instrumentation and fusion for thoracic hyperkyphosis: the sagittal stable vertebra concept. Spine 34:765-770

12. Lee SH, Kim KT, Suk KS, Lee JH, Seo EM, Huh DS (2011) Sagittal decompensation after corrective osteotomy for lumbar degenerative kyphosis: classification and risk factors. Spine (Phila Pa 1976) 36(8):E538-44. doi:10.1097/BRS.0b013e3 $181 \mathrm{f} 45 \mathrm{a} 17$

13. Cho KJ, Suk SI, Park SR, Kim JH, Kim SS, Lee TJ, Lee JJ, Lee JM (2008) Short fusion versus long fusion for degenerative lumbar scoliosis. Eur Spine J 17(5):650-656

14. Vialle R, Levassor N, Rillardon L, Templier A, Skalli W, Guigui P (2005) Radiographic analysis of the sagittal alignment and balance of the spine in asymptomatic subjects. J Bone Jt Surg Am 87:260-267

15. Neal CJ, McClendon J, Halpin R, Acosta FL, Koski T, Ondra SL (2011) Predicting ideal spinopelvic balance in adult spinal deformity. J Neurosurg Spine 15:82-91

16. Schwab F, Ungar B, Blondel B, Buchowski J, Coe J, Deinlein D, DeWald C, Mehdian H, Shaffrey C, Tribus C, Lafage V (2012) Scoliosis research society-Schwab adult spinal deformity classification: a validation study. Spine 37:1077-1082

17. Lowe T, Berven SH, Schwab FJ, Bridwell KH (2006) The SRS classification for adult spinal deformity: building on the King/Moe and Lenke classification systems. Spine 31(19 Suppl):S119-S125

18. Schwab FJ, Lafage V, Farcy JP, Bridwell KH, Glassman S, Shainline MR (2008) Predicting outcome and complications in the surgical treatment of adult scoliosis. Spine 33(20):2243-2247. doi:10.1097/BRS.0b013e31817d1d4e

19. Liu Y, Liu Z, Zhu F, Qian BP, Zhu Z, Xu L, Ding Y, Qiu Y (2013) Validation and reliability analysis of the new SRS-Schwab classification for adult spinal deformity. Spine 38(11):902-908

20. Terran J, Schwab F, Shaffrey CI, Smith JS, Devos P, Ames CP, Fu KM, Burton D, Hostin R, Klineberg E, Gupta M, Deviren V, Mundis G, Hart R, Bess S, Lafage V, International Spine Study Group (2013) The SRS-Schwab adult spinal deformity 
classification: assessment and clinical correlations based on a prospective operative and nonoperative cohort. Neurosurgery 73(4):559-568

21. Smith JS, Klineberg E, Schwab F, Shaffrey CI, Moal B, Ames CP, Hostin R, Fu KM, Burton D, Akbarnia B, Gupta M, Hart R, Bess S, Lafage V, International Spine Study Group (2013) Change in classification grade by the SRS-Schwab adult spinal deformity classification predicts impact on health-related quality of life measures: prospective analysis of operative and nonoperative treatment. Spine [Epub ahead of print]

22. Barrey C, Roussouly P, Le Huec JC, D’Acunzi G, Perrin G (2013) Compensatory mechanisms contributing to keep the sagittal balance of the spine. Eur Spine J 22(Suppl 6):S834-S841

23. Barrey C, Roussouly P, Perrin G, Le Huec JC (2011) Sagittal balance disorders in severe degenerative spine. Can we identify the compensatory mechanisms? Eur Spine J 20(Suppl 5):626-633
24. Obeid I, Hauger O, Aunoble S, Bourghli A, Pellet N, Vital JM (2011) Global analysis of sagittal spinal alignment in major deformities: correlation between lack of lumbar lordosis and flexion of the knee. Eur Spine J 20(Suppl 5):681-685

25. Berjano P, Lamartina C (2013) Far lateral approaches (XLIF) in adult scoliosis. Eur Spine J 22(Suppl 2):242-253

26. Savini R, Di Silvestre M, Gargiulo G (1988) Cervical osteotomy by the Simmons method in the treatment of cervical kyphosis due to ankylosing spondylitis. Case report. Ital J Orthop Traumatol 14(3):377-383

27. Langeloo DD, Journee HL, Pavlov PW, de Kleuver M (2006) Cervical osteotomy in ankylosing spondylitis: evaluation of new developments. Eur Spine J 15(4):493-500 [Epub 2005 Jun 1] 